\title{
Determination of Dynamic Fracture-initiation Toughness using Three-point Bending Tests in a Modified Hopkinson Pressure Bar
}

\author{
by L. Rubio, J. Fernández-Sáez and C. Navarro
}

\begin{abstract}
We present a procedure for measuring the dynamic fracture-initiation toughness of materials. The method is based on three-point bending tests at high loading rates, performed in an experimental device which is a modification of the classical split Hopkinson pressure bar. Coupled with the loading device, a high-speed photography system was used to measure the crack mouth opening displacement (CMOD) directly on the specimen. The stress intensity factor was calculated by three different simplified methods and the time to fracture was obtained from an appropriate specimen instrumentation. To evaluate the results derived from the simplified methods, a two-dimensional full-numerical analysis of the dynamic bending fracture test was made. The model includes the specimen, the input bar, the impacting projectile and the supporting device and takes into account the possible loss of contact during the experiment between the input bar and the specimen and between the specimen and its supports. From the tests and numerical results, it can be concluded that the CMOD procedure, together with the knowledge of the time to fracture determined using crack gages, seems to be the best method for measuring dynamic fracture-initiation toughness.
\end{abstract}

KEY WORDS - Dynamic bending test, stress intensity factor, numerical analysis, high strain rates

\section{Introduction}

Material fracture properties are often required for estimating the failure safety and damage tolerance design of structural components. As these components may be subjected to dynamic loading, the fracture properties should be measured at strain rates close to those that will be encountered in service.

The instrumented Charpy test has been widely used to evaluate the dynamic fracture properties of materials, the maximum loading rate (stress intensity factor (SIF) loading rate, $\dot{K}_{I}$ ) achieved during the test being about $\dot{K}_{I}=$ $10^{5} \mathrm{MPa} \sqrt{\mathrm{m} \mathrm{s}}{ }^{-1}$. For higher strain rates, different authors ${ }^{1-3}$ have described special arrangements of the split Hopkinson pressure bar (SHPB) apparatus for dynamic bending tests in such conditions.

Among fracture properties, the dynamic fracture-initiation toughness, $K_{I d}$ (the SIF at which a crack begins to grow) is of special importance. To obtain $K_{I d}$ experimentally, both

L. Rubio is a Senior Lecturer, J. Fernández-Sáez (ppfer@ing.uc3m.es) is a Professor and C. Navarro is a Professor, Department of Mechanical Engineering, Carlos III University of Madrid, Avda. de la Universidad, 30.28911 Leganés, Madrid, Spain. the temporal evolution of the SIF during the specimen loading process and the instant at which the crack begins to grow must be determined. Thus, $K_{I d}$ may be obtained as the SIF value at crack growth initiation time, $t_{f}$, i.e.,

$$
K_{I d}=K_{I}\left(t_{f}\right) \text {. }
$$

To calculate the SIF in dynamic bending tests, different optical $^{4-6}$ and photoelastic ${ }^{7}$ techniques have been proposed, but all require very complex equipment. Other authors, using the Euler-Bernoulli ${ }^{8}$ or Timoshenko ${ }^{9}$ beam theories, derived simple formulae for the dynamic SIF of three-point bending (TPB) specimens. To use these formulae, the applied load on the specimen and its natural frequencies must be known. Nishioka and Atluri ${ }^{10}$ computed the dynamic SIF from the crack mouth opening displacement (CMOD), assuming that the relationship deduced for static condition apply to the dynamic one. Bacon et al. ${ }^{3}$ rearranged the formula of Nishioka and Atluri ${ }^{10}$ to obtain the dynamic SIF from the load point displacement. Recently, Popelar et al. ${ }^{11}$ proposed a dynamic test method in which the fracture toughness is estimated from the crack opening displacement (COD). The COD is evaluated from CMOD (which is measured by means of a gage) using a simple quasi-dynamic model. The results of these models would be strictly applicable if pure TPB test conditions were maintained during the experiment, with no loss of contact between the specimen and the support device nor between the specimen and the input bar. However, Nishioka et al. ${ }^{12}$ first reported the evidence of this loss of contact in dynamic fracture tests, on the basis of numerical simulations. To take into account this possible loss of contact, different numerical approaches have been proposed to calculate the temporal evolution of the SIF in the TPB impact test. ${ }^{2,12,13}$

In this paper we propose an experimental procedure to measure the dynamic fracture-initiation toughness, $K_{I d}$. The test device, based on a modification of the conventional SHPB, allows dynamic fracture tests on TPB specimens at high loading rates $\left(\dot{K}_{I}=10^{6} \mathrm{MPa} \sqrt{\mathrm{m} \mathrm{s}^{-1}}\right)$. The experiments were conducted on TPB specimens of AA7075-T651 aluminum alloy. Once the input load, the load point displacement and the CMOD are experimentally obtained using the appropriate instrumentation, the SIF is calculated by different simplified methods. To measure the CMOD, a high-speed photography system was used, coupled to the modified SHPB device.

Two-dimensional finite element analysis of the modified SHPB TPB test (including projectile, input bar, specimen and 
supporting device) was carried out to compare the dynamic SIF values obtained from the different simplified procedures.

\section{Experimental Device}

The experimental device, based on the classical SHPB, consists (see Fig. 1) of a striker bar (projectile), an input bar, a specimen supporting device and an appropriate data acquisition system. The projectile and the input bar are cylindrical, $22 \mathrm{~mm}$ in diameter and $330 \mathrm{~mm}$ and $1 \mathrm{~m}$ long, respectively. The end of the input bar initially in contact with the specimen is geometrically similar to the nose of the hammer of the Charpy pendulum. The input bar is instrumented by strain gages (MEM Micromeasurements model CEA-06-1250N350 with a resistance of $350 \Omega$ and a gage length of $3.2 \mathrm{~mm}$ ) located on its surface at the mid-span section. This system, which consists of four strain gages, placed in a bridge circuit, allows the strain time-history to be measured at the input bar. The output signals measured by the strain gages are recorded at a sampling rate of $1 \mu \mathrm{s}$ and stored in a digital oscilloscope.

This device allows TPB specimens, whose geometry and dimensions accord with ASTM E399 Standard, ${ }^{14}$ to be tested.

To follow the specimen deformation throughout the dynamic TPB test, a high-speed photography system was coupled to the experimental device. The photographic equipment consists of four coupled CCD cameras with which to take images of a common objective (a 50 magnification lens) and from the same specimen zone. The specimen was illuminated from the side opposite to that from which the photographs are taken, so the images visualized the shadow of the specimen. Figure 2 shows the complete experimental setup with the relative position of the cameras, specimen and lighting system.

To synchronize the cameras with the mechanical test, a signal of a strain gage placed on the surface of the input bar near to the end impacted by the projectile was used. Only the first signal recorded at the strain gage is sent to the cameras. With this system it is possible to take up to 40 (10 per camera) different photographs of the specimen deformation process, but due to the time interval in which the initiation of crack propagation takes place (less than $50 \mu \mathrm{s}$ ) and the magnification selected for the images, the effective framing ratio is one photograph every $3 \mu \mathrm{s}$, approximately. Then the photographs were computer treated to obtain enhanced images from which direct measurement of displacements, such as CMOD, can be made with errors less than $0.02 \mathrm{~mm}$.

To evaluate the time to fracture, the specimens were instrumented in two different ways. Several were instrumented with a small strain gage (with a gage length of $0.3 \mathrm{~mm}$ ) bonded near the crack tip at a distance of approximately $2 \mathrm{~mm}$ from the crack path, as shown in Fig. 3(a). In others, a crack gage was placed just at the crack tip (see Fig. 3(b)).

\section{Test Procedure}

The specimen was placed on the TPB device and the system was carefully aligned to guarantee that the crack surface and contact line of the input bar with the specimen were in the same plane.

The impact of the projectile at the desired velocity, $V_{0}$, generates a longitudinal traveling compressive pulse, $\varepsilon_{i}(t)$, in the input bar. Part of this pulse energy is transmitted to the specimen and the supporting device, while the rest is reflected back to the input bar as a tensile pulse, $\varepsilon_{r}(t)$. From the onedimensional elastic wave propagation theory, the input load, $P(t)$, and the displacement of the bar edge initially in contact with the specimen, $u(t)$, can be calculated as ${ }^{1,2}$

$$
\begin{gathered}
P(t)=E A\left(\varepsilon_{i}(t)+\varepsilon_{r}(t)\right) \\
u(t)=c_{0} \int_{0}^{t}\left(\varepsilon_{i}(\tau)-\varepsilon_{r}(\tau)\right) \mathrm{d} \tau,
\end{gathered}
$$

where $A$ and $E$ are, respectively, the cross-sectional area and the material Young's modulus of the input bar, and $c_{0}$ is the sound speed in the bar $\left(c_{0}=\sqrt{\frac{E}{\rho}}, \rho\right.$ being its mass density).

To directly measure the CMOD, images were captured throughout the test by the high-speed photography system and stored in a computer for their subsequent processing. The signal recorded from the specimen instrumentation was stored in an oscilloscope to determine the time to fracture.

\section{$K_{I d}$ Determination}

The evaluation of the dynamic fracture-initiation toughness of the material involves two key items: first, the calculation of the temporal evolution of the SIF; and secondly, the time to fracture measurement. For the first, three different approaches (based on the input load, load point displacement and the CMOD, see Fig. 4) were used.

The SIF may be computed ${ }^{8}$ from the applied load, $P(t)$

$$
\frac{K_{I}(t)}{K_{I S}}=\frac{\omega_{1}}{P(t)} \int_{0}^{t} P(\tau) \sin \omega_{1}(t-\tau) \mathrm{d} \tau
$$

where $\omega_{1}$ is the fundamental frequency of the simplysupported cracked beam. $K_{I S}$ is the static SIF corresponding to the load $P(t)$, written as ${ }^{15}$

$$
K_{I s}=\frac{3}{2} \frac{P(t) \beta}{B \sqrt{W}} \frac{\sqrt{\alpha}}{(1+2 \alpha)(1-\alpha)^{3 / 2}} f(\alpha)
$$

with

$$
f(\alpha)=\left(1.99-\alpha(1-\alpha)\left(2.15-3.93 \alpha+2.7 \alpha^{2}\right)\right)
$$

where $\alpha$ is the ratio between the crack length, $a$, and the specimen width, $W$.

For the specimen tested, the parameter $\beta$ (defined as the ratio between the specimen span, $S$, and its width, $W$ ) was 4 , so the shear and rotary inertia effects had to be taken into account in the calculation of the fundamental frequency, $\omega_{1}$. Rubio et al. ${ }^{16}$ evaluated this parameter considering these effects. A closed expression for $\omega_{1}$ is given in Appendix 1 .

Another way to calculate the SIF is that derived from the load point displacement, $u_{P}(t)$. Assuming that the relationship deduced for static conditions is applicable to the dynamic one, ${ }^{3}$ it can be written as

$$
K_{I}(t)=\frac{3}{2} \frac{\beta}{B \sqrt{W}} \frac{u_{P}(t)}{C(\alpha)} k_{\beta}(\alpha)
$$




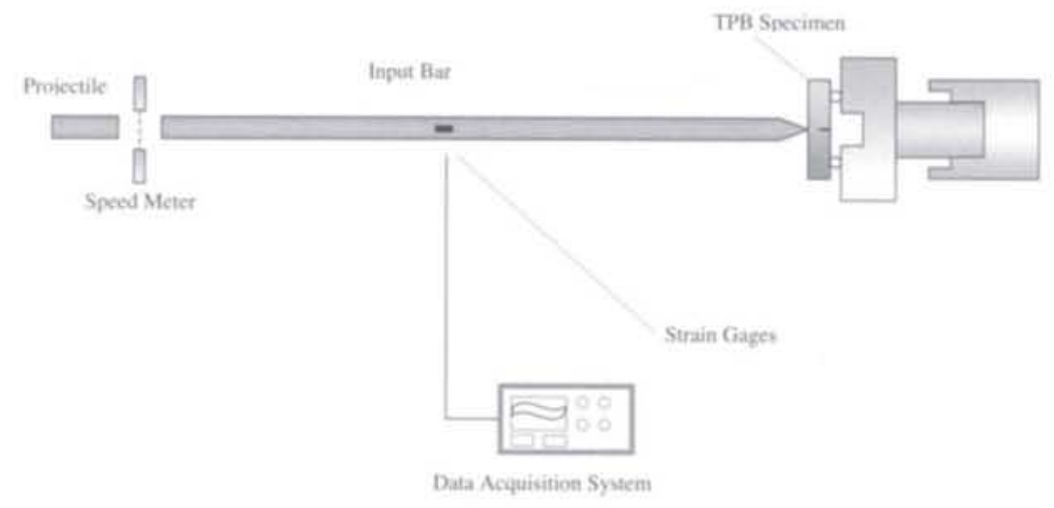

Fig. 1-Modified split Hopkinson pressure bar device

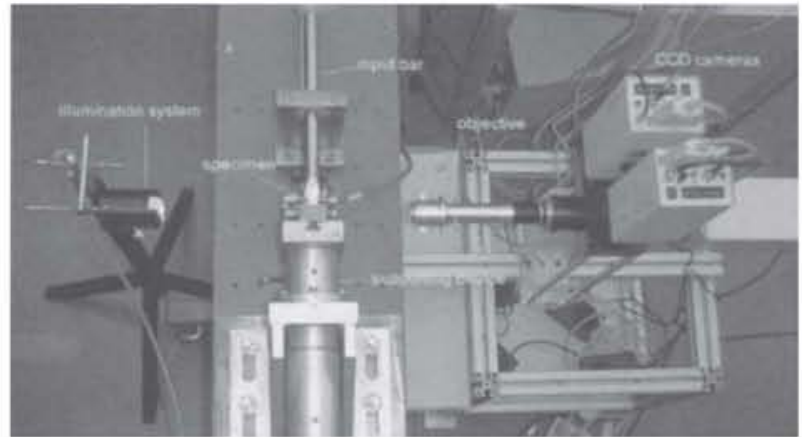

Fig. 2-Overall view of the test setup

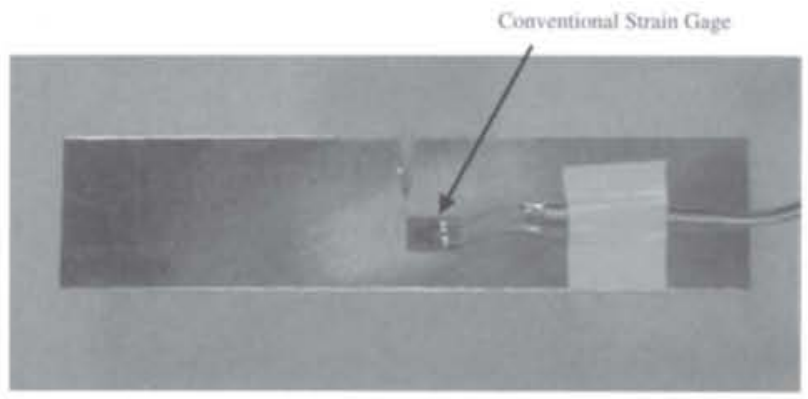

(a)

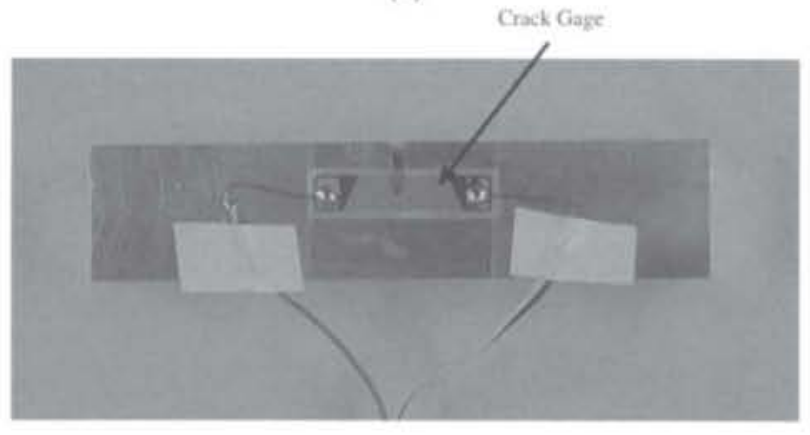

(b)

Fig. 3-Specimen instrumentation: (a) conventional strain gage, (b) crack gage

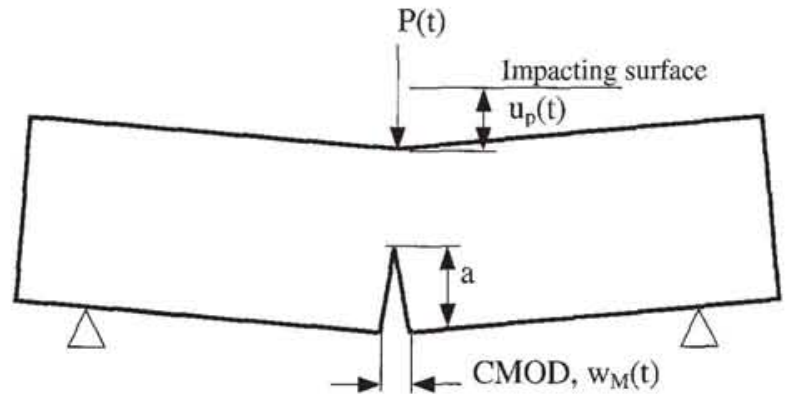

Fig. 4-Schematic view of the deformation of the TPB specimen

where $C(\alpha)$ is the compliance of the cracked specimen (its expression is given in Appendix 2) and $k_{\beta}(\alpha)$ is a nondimensional function depending on the variables $\alpha$ and $\beta$. Its expression can be found in Guinea et al. ${ }^{17}$ and, for the case $\beta=4$, in Appendix 3. For simplicity, the load point displacement, $u_{P}(t)$, was assumed to be equal to that of the edge of the input bar, $u_{t}$. However, these displacements are only equal if there is no contact loss between the input bar edge and the specimen during the test.

Alternatively, the SIF may be evaluated from the CMOD values, $w_{M}(t)$, again assuming that the relationship of the static case applies to the dynamic one. ${ }^{10}$ In this case $K_{I}(t)$ is written as

$$
K_{I}(t)=\frac{E w_{M}}{4 \sqrt{a \alpha}} \frac{k_{\beta}(\alpha)}{v_{\beta}(\alpha)} .
$$

In this last equation, $k_{\beta}(\alpha)$ is the same function appearing in eq (6) and $v_{\beta}(\alpha)$ is a non-dimensional function depending on $\alpha$ and $\beta$ values, and its expression can be found in Guinea et al. ${ }^{17}$ For the case $\beta=4, v_{\beta}(\alpha)$ is given in Appendix 3 .

Therefore, from the knowledge of either the input load (eq (4)), or the load point displacement (eq (6)), or the CMOD (eq (7)) time-histories, the SIF at any time of the test can be evaluated.

In addition, from the analysis of the signals of the strain gages or the crack gages placed on the specimens, the time 
to fracture was measured. Once $K_{I}(t)$ has been determined by one of the three simplified procedures given above, and once the time to fracture is known, $K_{I d}$ may be obtained by eq (1).

\section{Experimental Results}

The experiment was conducted on TPB specimens machined from an AA7075-T651 aluminum alloy plate. The chemical composition and the static mechanical properties of the material at room temperature are listed in Tables 1 and 2 , respectively. The relative dimensions of the specimens are: width, $W=20 \mathrm{~mm}$; thickness, $B=10 \mathrm{~mm}$; length, $L=90 \mathrm{~mm}$. The specimens were notched in the $T-L$ direction ${ }^{14}$ and fatigue pre-cracked in a $100 \mathrm{kN}$ servohydraulic machine (Instron 8506) to obtain a crack length of about $50 \%$ of the specimen width. A fixed support span $(S=80 \mathrm{~mm})$ was used in all the tests.

Table 3, summarizing the experimental results, contains the following information: specimen number; initial crack length, $a_{0}$; the impact velocity of the projectile, $V_{0}$; the time to fracture, $t_{f}$; the kind of strain gage used to measure the time to fracture, conventional strain gage (CSG) or crack gage (CG); the values of $K_{I d}$ evaluated from the input load, $P(t), K_{P}^{*}$, from the displacement $u, K_{u}^{*}$; and finally, from CMOD, $K_{C M O D}^{*}$.

As an example, the experimental results of a particular test (specimen number 9) are presented in detail. Figures 5(a) and 5(b) show, respectively, the time-histories of the applied load, $P(t)$ (eq (2)) and the displacement of the bar end initially in contact with the specimen, $u(t)$ (eq (3)). Photographs taken by the four cameras during the test are shown in Fig. 6(a) and the corresponding computer-treated images in Fig. 6(b). In these figures, several photographs can be recognized in the frames corresponding to each camera, in particular: six photographs for camera number one in the time interval $t=$ $10-35 \mu \mathrm{s}$; six photographs between $t=12-60 \mu \mathrm{s}$ for camera number two; six photographs for camera number three in the time interval $t=13-73 \mu \mathrm{s}$; and finally, five photographs from $t=27-87 \mu$ s taken by camera number four. From the images of Fig. 6(b), CMOD was directly measured. From the experimental results of the SIF, time-histories using the simplified procedures can be seen in Fig. 7. In these figures, the axis time origin corresponds to the instant at which the incident wave reaches the specimen, i.e., $98 \mu$ s after passing through the strain gage at the mid-span of the incident bar.

The time to fracture was obtained from the signals of the specimen instrumentation. Figures 8(a) and 8(b) show typical signals from the conventional strain gage (see Fig. 3(a)) and from the crack gage (Fig. 3(b)). In both cases, the time to fracture corresponds to the time at which the maximum of the electrical voltage curve versus time is reached. In particular, Fig. 8(b) corresponds to the signal recorded by the crack gage placed on specimen number 9 . In this case, the signal of the gage located on the specimen is recorded from the instant at which the incident wave reaches the strain gage of the input bar.

\section{Numerical Simulation}

To compare different simplified methods of obtaining the dynamic SIF, a numerical simulation of the impact bending fracture test, corresponding to specimen number 9 , was

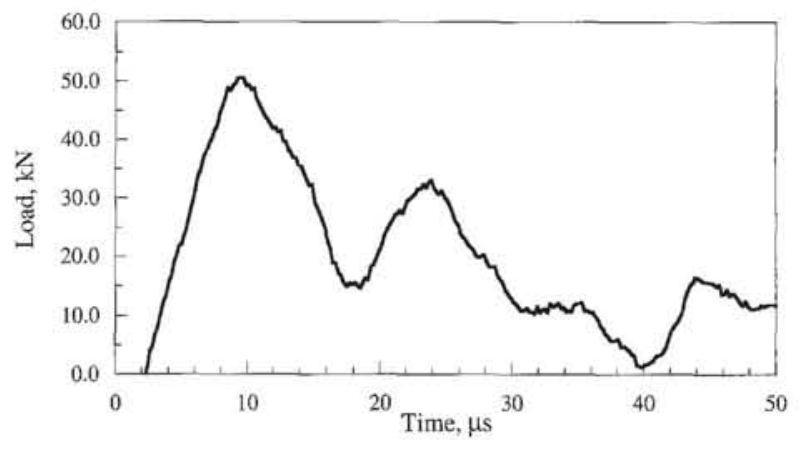

(a)

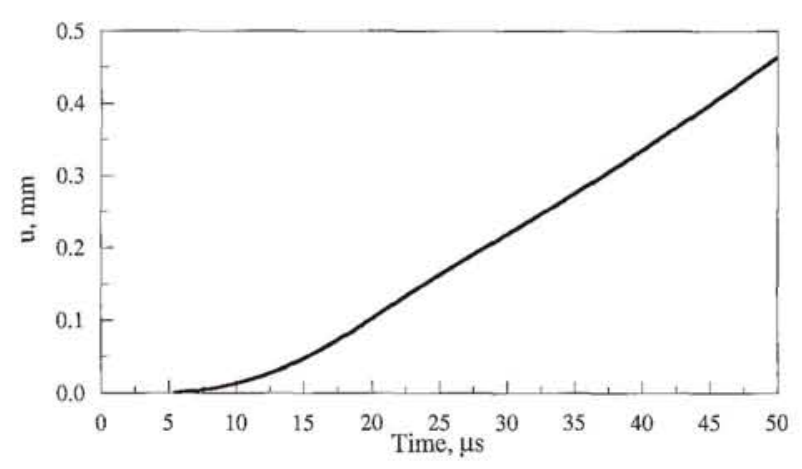

(b)

Fig. 5-Experimental results for specimen number 9: (a) input load time-history, (b) displacement of the end of input bar time-history

performed using the finite element method commercial computer code, ABAQUS. ${ }^{18}$ The finite element model included the projectile, the input bar, the specimen and its supporting device. The simulated specimen had a fatigue crack of length $a=0.54 \mathrm{~W}$. Due to symmetry, only one half of the specimen, input bar and projectile, and only one support were modeled. The mesh of the specimen consisted of 1244 nodes and 1180 four-node plane-strain bilinear reduced-integration elements. To take into account the stress and strain concentrations at the crack tip, the mesh was refined at that zone, with the smallest element side size being $45 \mu \mathrm{m}$. The input bar mesh consisted of 1972 nodes and 1570 elements, and that of the projectile had 624 nodes and 495 elements. In this case, four-node plane-stress bilinear reduced-integration elements were used. The thickness of these elements was chosen in such a way that the total bar cross-section was preserved. The supporting device was modeled by a half-roller $8 \mathrm{~mm}$ in diameter. To simulate the rest of the support, 18 special elements called "infinity elements" (CINPE4) provided by the ABAQUS finite element package ${ }^{18}$ were added. This kind of element is often used in boundary value problems defined in unbounded domains, or for problems in which the region of interest is small in comparison with the surrounding medium. In this dynamic analysis, the infinity elements were chosen for their ability to transmit energy outside the finite element mesh, without trapping or reflecting it. This transmission is optimized when the boundary between finite and infinite elements is orthogonal to the direction from which the waves will impinge on this boundary. ${ }^{18}$ 


\begin{tabular}{cccccccc}
\hline $\mathrm{Si}$ & $\mathrm{Fe}$ & $\mathrm{Cu}$ & $\mathrm{Mn}$ & $\mathrm{Mg}$ & $\mathrm{Zn}$ & $\mathrm{Ti}$ & $\mathrm{Al}$ \\
\hline 0.100 & 0.160 & 1.620 & 0.050 & 2.620 & 5.870 & 0.036 & $\mathrm{Bal}$
\end{tabular}

TABLE 2-MECHANICAL PROPERTIES OF THE AA7075-T651 ALLOY

\begin{tabular}{cccccc}
\hline $\begin{array}{c}\text { Young's Modulus } \\
E(\mathrm{GPa})\end{array}$ & $\begin{array}{c}\text { Yield Strength } \\
\sigma_{0.2}(\mathrm{MPa})\end{array}$ & $\begin{array}{c}\text { Ultimate Strength } \\
\sigma_{\text {UTS }}(\mathrm{MPa})\end{array}$ & $\begin{array}{c}\text { Poisson's Ratio } \\
\nu\end{array}$ & $\begin{array}{c}\text { Elongation } \\
\delta(\%)\end{array}$ & $\begin{array}{c}\text { Mass Density } \\
\rho\left(\mathrm{kg} \mathrm{m}^{-3}\right)\end{array}$ \\
\hline 72 & 524 & 587 & 0.3 & 12.7 & 2800
\end{tabular}

TABLE 3-EXPERIMENTAL RESULTS

\begin{tabular}{cccccccc}
\hline $\begin{array}{c}\text { Specimen } \\
\text { Number }\end{array}$ & $\begin{array}{c}a_{0} \\
(\mathrm{~mm})\end{array}$ & $\begin{array}{c}V_{0} \\
\left(\mathrm{~m} \mathrm{~s}^{-1}\right)\end{array}$ & $\begin{array}{c}\text { Strain } \\
\text { Gage }\end{array}$ & $\begin{array}{c}t_{f} \\
(\mu \mathrm{s})\end{array}$ & $\begin{array}{c}K_{P}^{*} \\
\left(\mathrm{MPa} \mathrm{m}^{1 / 2}\right)\end{array}$ & $\begin{array}{c}K_{u}^{*} \\
\left(\mathrm{MPa} \mathrm{m}^{1 / 2}\right)\end{array}$ & $\begin{array}{c}K_{C M O D}^{*} \\
\left(\mathrm{MPa} \mathrm{m} \mathrm{m}^{1 / 2}\right)\end{array}$ \\
\hline 31 & 11.33 & 13.1 & CSG & 28 & 30 & 25 & 29 \\
28 & 11.54 & 12.8 & CG & 32 & 34 & 29 & 33 \\
30 & 11.23 & 12.9 & CG & 31 & 34 & 29 & 34 \\
32 & 11.76 & 12.7 & CSG & 29 & 37 & 26 & 37 \\
9 & 10.81 & 13.1 & CG & 25 & 25 & 22 & 26 \\
8 & 11.79 & 13.0 & CSG & 25 & 29 & 21 & 32 \\
7 & 11.03 & 12.9 & CG & 32 & 36 & 30 & 31 \\
10 & 10.73 & 13.2 & CSG & 25 & 33 & 20 & 28 \\
Mean values & & & & 28 & 32 & 25 & 31 \\
Standard deviation & & & & 3.1 & 4.0 & 3.9 & 3.8
\end{tabular}

It is worth noting that, by means of this analysis, the possible loss of contact between specimen and input bar or/and specimen and supports is properly taken into account.

Figure 9 shows the meshes of the specimen, the end of the input bar, and the support used in the analysis. Linear elastic behavior was assumed for all the materials involved. The elastic properties of the projectile, input bar and support material were of elastic limit silver steel with Young's modulus $E=200 \mathrm{GPa}$ and Poisson's ratio $\nu=0.3$, and a mass density of $\rho=7850 \mathrm{~kg} \mathrm{~m}^{-3}$. The elastic properties and mass density of the specimen material correspond to those of the AA7075-T651 aluminum alloy and are given in Table 2. The projectile impact velocity considered was $13.1 \mathrm{~m} \mathrm{~s}^{-1}$.

In this analysis, we used the Hilber-Hughes-Taylor directintegration method, implemented in the ABAQUS code. ${ }^{18} \mathrm{It}$ is an implicit method, unconditionally stable for linear systems. In all the analyses, a time increment of $1 \mu$ s was taken for the integration process.

The SIF can be obtained from the general pathindependent dynamic $J$ integral, $J^{\prime}$, derived by Nishioka and Atluri $^{19}$ (see also Nishioka ${ }^{20}$ ). For a mode I stationary crack (as in our case) the SIF may be derived as ${ }^{19,20}$

$$
K_{I}(t)=\sqrt{\frac{E J_{1}^{\prime}(t)}{1-v^{2}}}
$$

From the numerical results, corresponding to the first $100 \mu \mathrm{s}$ of the test, the temporal evolution of the following variables was obtained: the difference between the displacements of the specimen loading point and the end of the input bar (Fig. 10(a)), the displacement of the point of the specimen initially in contact with the support (Fig. 10(b)), and finally the SIF deduced from eq (8) and those derived from the input load (eqs (2) and (4)), the displacement on the input bar end (eqs (3) and (6)) and the CMOD (eq (7)) (see Fig. 11).

\section{Discussion}

From the experimental results (Fig. 7), the SIF evaluated from the input load is lower than that obtained by other procedures in the first $20 \mu \mathrm{s}$ of the test. For times longer than $30 \mu \mathrm{s}$, the SIF values calculated from the displacement clearly differ from those calculated by the other two methods. This may be because around this time the crack starts to grow (the time to fracture measured for this specimen is $25 \mu \mathrm{s}$ ) and contact is lost between the specimen and the end of the bar.

For the determination of the time to fracture (Table 3), it may be deduced that the mean value of the time to fracture obtained with the conventional strain gage (four tests) is $27 \mu \mathrm{s}$, whereas the corresponding values obtained from the crack gage (four tests) is $30 \mu \mathrm{s}$. Since the crack gages are placed just at the crack tip, the measurement of the time to fracture with this kind of gage is more precise than with conventional gages.

The numerical results (Figs. 10(a) and 10(b)) show that during the first $15 \mu \mathrm{s}$, the specimen was subjected to a pure TPB test. In the time interval between $t=15-50 \mu \mathrm{s}$, the specimen behaves as subjected to a one-point bending test because of the contact loss between specimen and supports, and in the interval between $50-55 \mu$ s the specimen moves freely without any contact with the input bar or with its supports. Between $t=55-60 \mu \mathrm{s}$, the specimen is in contact with the supports, but not with the input bar. Finally, after $t=60 \mu \mathrm{s}$, the conditions are again those of a pure TPB test. The same phenomenon was first elucidated by Nisioka et al. ${ }^{12}$

Since the time to fracture experimentally measured for the given specimen is $25 \mu \mathrm{s}$, it is subjected to a one-point bending test at the onset of crack propagation. However, Fig. 11 shows that, throughout the test, only the SIF values numerically obtained from the CMOD were very close to the numerical values calculated by eq (8). This indicates the possibility of 


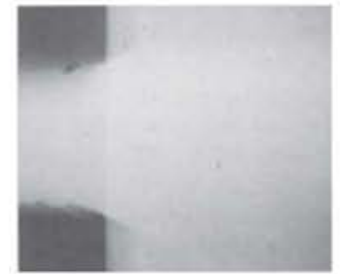

Camera 1

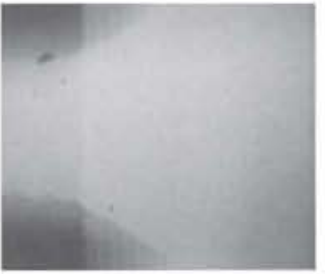

Camera 3

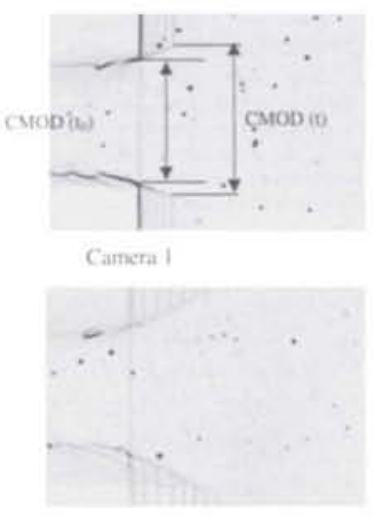

Camera 3

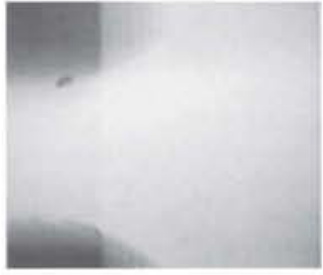

Camera 2

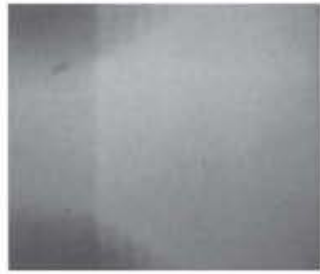

Camera 4

(a)

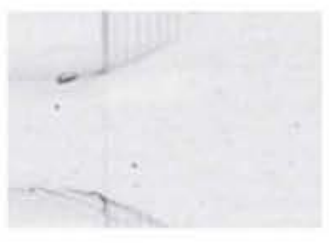

Camera 2

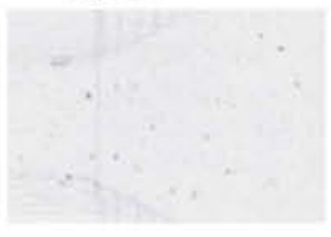

Camera 4 (b)

Fig. 6-Photographs taken by the CCD cameras. (a) Asobtained: camera 1 (six photographs from $t=10-35 \mu \mathrm{s}$ ); camera 2 (six photographs from $t=12-60 \mu \mathrm{s}$ ); camera 3 (six photographs from $t=13-73 \mu \mathrm{s}$ ); camera 4 (five photographs from $t=27-87 \mu \mathrm{s}$ ). (b) Computer-treated

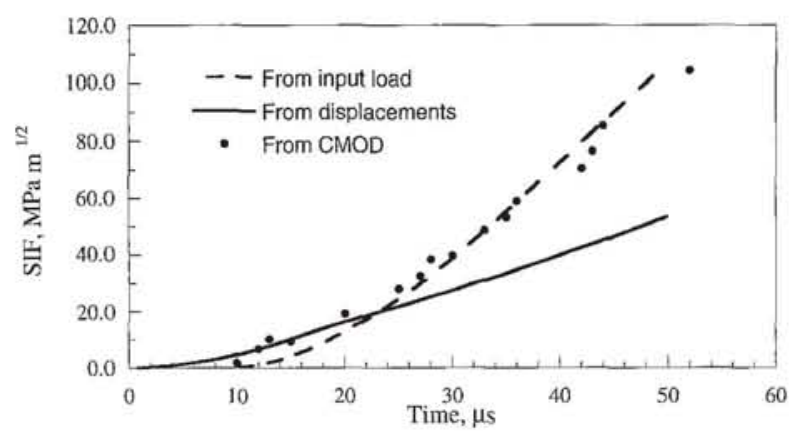

Fig. 7-Experimental determination of the SIF by three different procedures

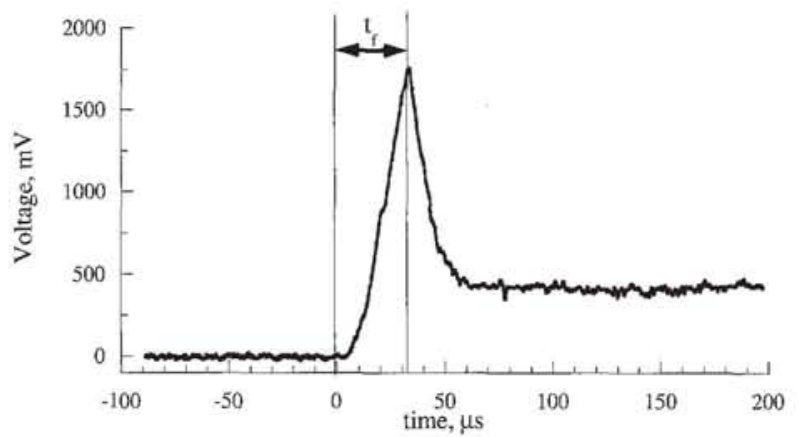

(a)

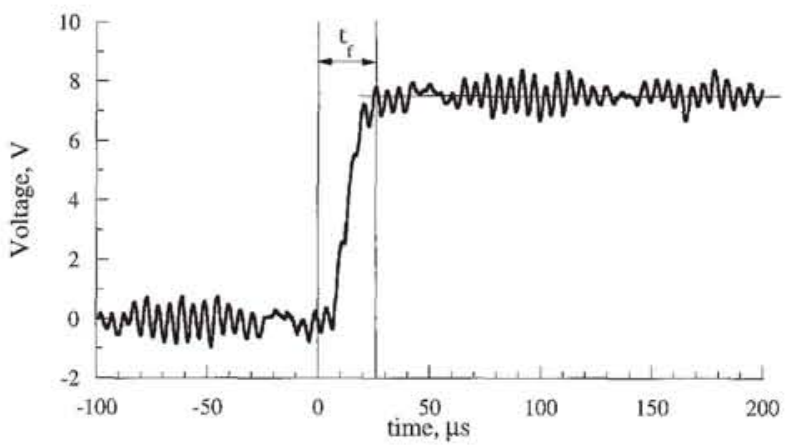

(b)

Fig. 8-Time to fracture determination: (a) conventional strain gage signal, (b) crack gage signal

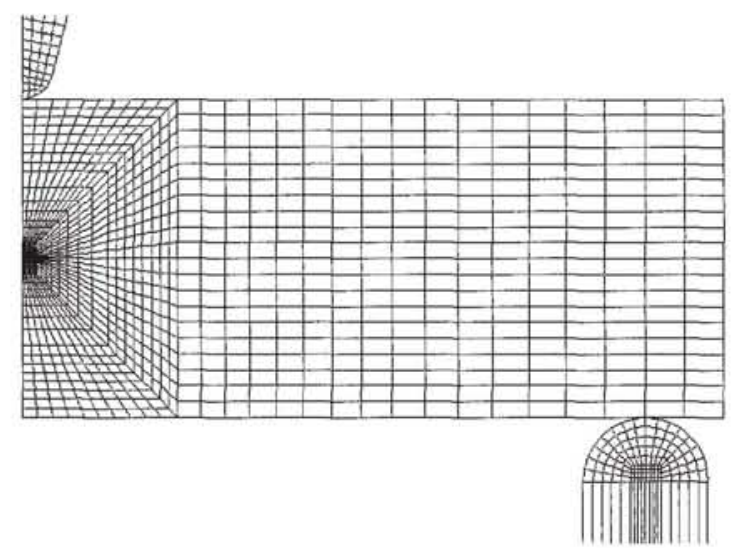

Fig. 9-Meshes used in the numerical analysis

obtaining the SIF from the CMOD using the relationship that applies in the static conditions for TPB specimens, even when the actual test is a one-point bending test. The same conclusion was found by Nishioka and Atluri. ${ }^{10}$

Figure 12 shows a comparison between the SIF obtained experimentally with the three different procedures and the SIF numerically calculated by eq (8). Since all the analyses considered non-crack propagation, the results after the time to fracture are not representative. As shown in this Fig. 12, for the case considered, in which the measured time to fracture is $25 \mu \mathrm{s}$, the values of $K_{I d}$ obtained with the different procedures were practically coincident. These results were similar 


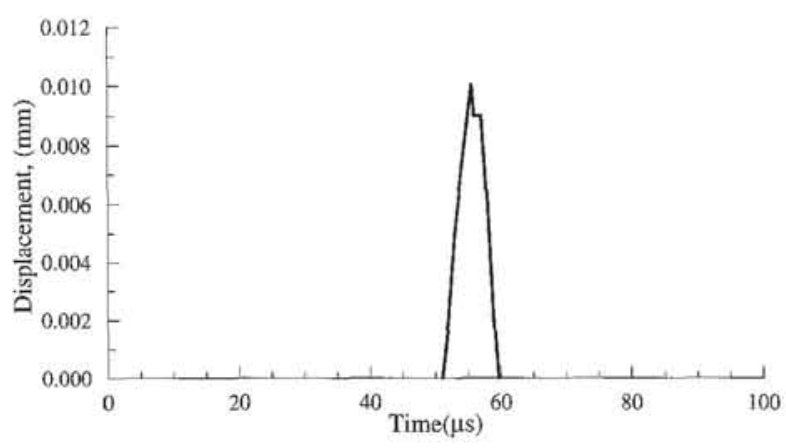

(a)

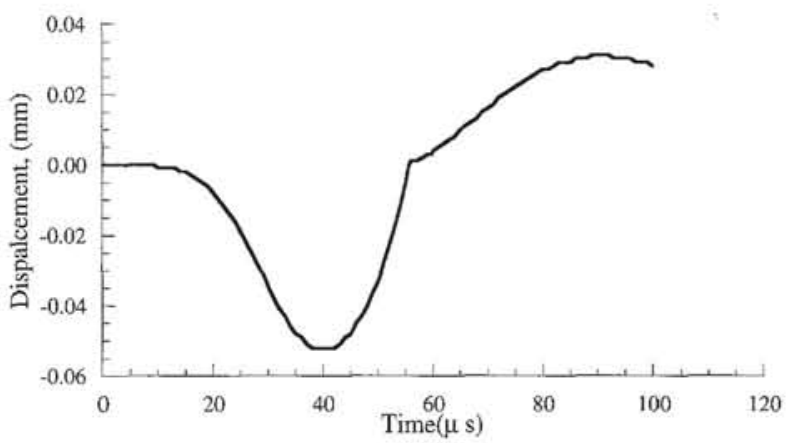

(b)

Fig. 10-Numerical results: (a) relative displacement between the specimen and the input bar, (b) displacement of the specimen point initially in contact with the support

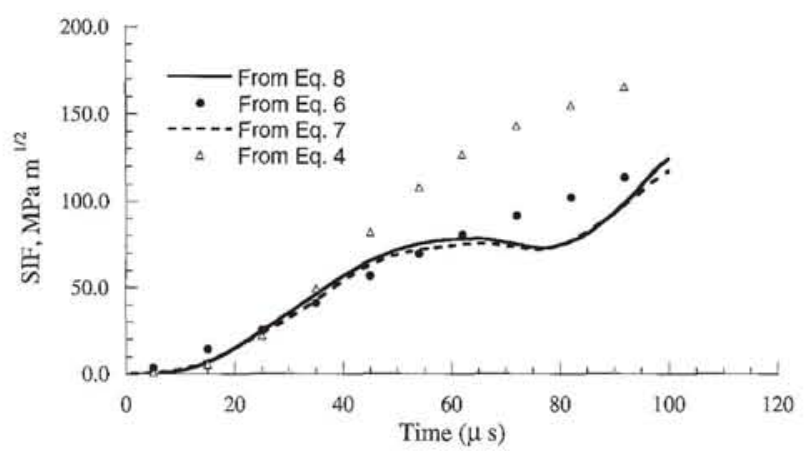

Fig. 11-Numerical determination of the SIF by different procedures

in all the specimens tested (see Table 3 ) and it can be seen that the loading rates reached were about $\dot{K}_{I}=10^{6} \mathrm{MPa} \sqrt{\mathrm{m}} \mathrm{s}^{-1}$. The values of $K_{I d}$ and $\dot{K}_{I}$ coincide with those reported by Yokoyama. $^{2}$

\section{Summary and Conclusions}

We have presented a procedure to evaluate dynamic fracture-initiation toughness. It is based on dynamic fracture tests performed on TPB specimens, in conjunction with a high-speed photography technique which provides direct measurement of the CMOD. This experimental technique allows high loading rates $\left(\dot{K}_{I}=10^{6} \mathrm{MPa} \sqrt{\mathrm{m}} \mathrm{s}^{-1}\right)$. The dy-

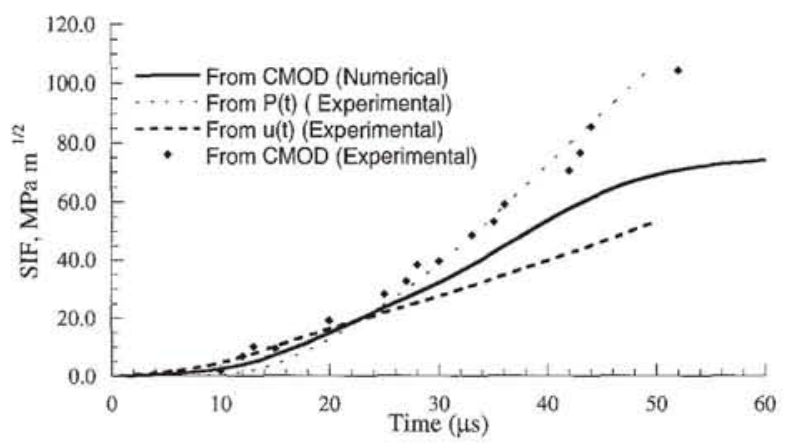

Fig. 12-Comparison between numerical and experimental determination of the SIF

namic fracture-initiation toughness is determined as the SIF at the time to fracture.

The dynamic SIF was calculated by three different simplified methods and the time to fracture was obtained by an appropriate instrumentation of the specimen. To evaluate these different procedures, a two-dimensional numerical analysis of the dynamic bending fracture test was performed. The model included the specimen, the input bar, the impacting projectile and the supporting device, and took into account the possible loss of contact between the loading bar and the specimen and between the specimen and its support system during the experiment.

From the tests and numerical results, it can be concluded that the best way to estimate dynamic fracture-initiation toughness is to determine the SIF from the CMOD, and the time to fracture from crack gages bonded on the specimen.

\section{Appendix 1. Fundamental Frequency of the Cracked Specimen}

The value of $\omega_{1}$, appearing in eq (4) can be calculated by the following expression ${ }^{16}$

$$
\omega_{1}=\left(\frac{\pi}{L}\right)^{2} \sqrt{\frac{E I}{\rho A}}\left(\frac{1+\gamma_{1}+2 h(\alpha)}{k_{1}+k_{2} h(\alpha)+k_{3} h^{2}(\alpha)}\right)^{1 / 2}
$$

where

$$
h(\alpha)=\frac{1}{\beta} m(\alpha) .
$$

$m(\alpha)$ is a function of $\alpha\left(\alpha=\frac{a}{W}\right)$ and the section geometry. In the case of a rectangular section, the function $m(\alpha)$ can be expressed as ${ }^{15}$

$$
m(\alpha)=2\left(\frac{\alpha}{1-\alpha}\right)^{2} f(\alpha)
$$

where

$$
f(\alpha)=5.93-19.69 \alpha+37.14 \alpha^{2}-35.84 \alpha^{3}+13.12 \alpha^{4} .
$$

The constants $k_{1}, k_{2}$ and $k_{3}$ are given by

$$
k_{1}=\left(1+\gamma_{1}\right)^{2}+\gamma_{2}
$$




$$
\begin{gathered}
k_{2}=4\left(1+\gamma_{1}+\gamma_{2}\right) \\
k_{3}=\frac{\pi^{4}}{24}+\frac{\pi^{2}}{2} \gamma_{2}
\end{gathered}
$$

with

$$
\begin{gathered}
\gamma_{1}=\frac{2(1+v)}{\kappa} \frac{I}{A}\left(\frac{\pi}{L}\right)^{2} \\
\gamma_{2}=\frac{I}{A}\left(\frac{\pi}{L}\right)^{2} .
\end{gathered}
$$

$\nu$ is the Poisson's ratio of the material and $\kappa$ is the shear coefficient ( $5 / 6$ for a rectangular section).

\section{Appendix 2. Compliance of the Cracked Specimen}

The compliance of the cracked specimen is given by

$$
C(\alpha)=C_{0}+C_{c}(\alpha)
$$

where $C_{0}$ is the compliance of the specimen with any crack that can be calculated as

$$
C_{0}=\frac{L^{3}}{48 E I}\left(1+\frac{24(1+v)}{\kappa} \frac{I}{A L^{2}}\right) .
$$

$C_{c}(\alpha)$ takes into account the effect of the crack in the compliance of the specimen and its expression is ${ }^{17}$

$$
C_{c}(\alpha)=\frac{1}{E B}\left[h_{1}(\alpha)+\beta h_{2}(\alpha)+\beta^{2} h_{3}(\alpha)\right]
$$

with

$$
h_{1}(\alpha)=-0.378 \alpha^{3} \ln (1-\alpha)+\alpha^{2} \frac{0.29+1.39 \alpha-1.62 \alpha^{2}}{1+0.54 \alpha-0.84 \alpha^{2}}
$$

$$
\begin{aligned}
h_{2}(\alpha)= & 1.1 \alpha^{3} \ln (1-\alpha) \\
& +\alpha^{2} \frac{-3.22-16.4 \alpha+28.1 \alpha^{2}-11.4 \alpha^{3}}{(1-\alpha)\left(1+4.7 \alpha-4 \alpha^{2}\right)} \\
h_{3}(\alpha)= & -0.176 \alpha^{3} \ln (1-\alpha) \\
& +\alpha^{2} \frac{8.91-4.88 \alpha-0.435 \alpha^{2}+0.26 \alpha^{3}}{(1-\alpha)^{2}(1+2.9 \alpha)} .
\end{aligned}
$$

\section{Appendix 3. Expressions of Functions $k_{\beta}(\alpha)$ and} $v_{\beta}(\alpha)$

The expressions of $k_{\beta}(\alpha)$ and $v_{\beta}(\alpha)$, for the particular case of $\beta=4$, are $^{17}$

$$
\begin{aligned}
k_{\beta}(\alpha)= & \frac{\sqrt{\alpha}}{(1-\alpha)^{3 / 2}(1+3 \alpha)} \\
& \left(1.9+0.41 \alpha+0.51 \alpha^{2}-0.17 \alpha^{3}\right)
\end{aligned}
$$

$$
v_{\beta}(\alpha)=0.76-2.28 \alpha+3.87 \alpha^{2}-2.04 \alpha^{3}+\frac{0.66}{(1-\alpha)^{2}} .
$$

\section{Acknowledgment}

This work was supported by the Comisión Interministerial de Ciencia y Tecnología under Grant PB98-0027.

\section{References}

I. Ruiz, C. and Mines, R., "The Hopkinson Pressure Bar: An Alternative to the Instrumented Pendulum for Charpy Test," Int. J. Fracture, 29 (2), 101-109 (1985).

2. Yokoyama, T., "Determination of Dynamic Fracture-initiation Toughness Using a Novel Impact Bend Test Procedure," J. Pressure Vessel Technol., 115 (2), 389-397 (1993).

3. Bacon, C., Färm, J., and Lataillade, J., "Dynamic Fracture Toughness Determined from Load-point Displacement," EXPERIMENTAL MECHANICS, 20 (1), 217-223 (1994).

4. Beinert, J. and Kalthoff, J., "Experimental Determination of Dynamic Stress Intensity Factors by Shadow Patterns," in Mechanics of Fracture, G. Sih (ed), Vol. 7, Martinus Nijhoff. The Hague, 281-330 (1981).

5. Ravi-Chandar, $K$. and Knauss, W. "An Experimental Investigation Into Dynamic Fracture: 1. Crack Initiation and Arrest," Int. J. Fracture, 25, 247-262 (1984)

6. Benitez, F. and Andrade, L., "In-plane Impact Loading of Composites: Optical Evaluation and Crack Severity Assessment for GraphiteEpoxy," J. Physique IV, 7, C3-169-176 (1997).

7. Dally, J. and Barker, D., "Dynamic Measurements of Initiation Toughness at High Loading Rates," EXPERIMENTAL MECHANICS, 28 (3), 298-303 (1988).

8. Kishimoto, K., Aoki, S., and Sakata, M., "Simple Formula for Dynamic Stress Intensity Factor of Pre-cracked Charpy Specimen," Eng. Fracture Mech., 13 (3), 501-508 (1980).

9. Kisihimoto, K., Kuroda, K., Aoki, S., and Sakata, M., "Simple Formulae for Dynamic Fracture Mechanics Parameters of Elastic and Viscoelastic Three-point Bend Specimens Based on Timoshenko's Beam Theory," Proc. 6th Int. Conf. on Fracture, New Delhi, India. S. Valluri et al. (eds). Vol. S, Pergamon, Oxford, 3177-3184 (1984).

10. Nishioka, T. and Atluri, S., "A Method for Determining Dynamic Stress Intensity Factors from COD Measurement at the Notch Mouth in Dynamic Tear Testing," Eng. Fracture Mech., 16 (3), 333-339 (1982).

11. Popelar, C., Anderson Jr, C, and Nagy, A., "An Experimental Method for Determining Dynamic Fracture Toughness," EXPERIMENTAL MECHANICS, 40 (4), 401-407 (2000).

12. Nishioka, T., Perl, M., and Atluri, S., "An Analysis of Dynamic Fracture in an Impact Test Specimen," J. Pressure Vessel Technol., 105, 124-131 (1983).

13. Crouch, B., "Finite Element Modeling of the Three-point Bend Impact Test," Comput. Struct., 48 (4), 167-173 (1993).

14. American Society for Testing and Materials, ASTM E399-93 Standard Test Method for Plane Strain Fracture Toughness of Metallic Materials, Annual Book of ASTM Standards, Vol. 03.01, Philadelphia, PA (1983).

15. Tada, H., Paris, P., and Irwin, G., "The Stress Analysis of Cracks Handbook," 2nd edition, Paris Productions, Inc., St Louis (1985).

16. Rubio, L., Fernández-Sáez, J., and Navarro, C., "Factor de Intensidad de Tensiones Dinámico en Probetas de Flexión en Tres Puntos y de Flexión en un Punto Sometidas a Pulsos de Carga de Corta Duración," Anales de Mecánica de la Fractura, 15, 97-101 (1998).

17. Guinea, G., Pastor, J., Planas, J., and Elices, M., "Stress Intensity Factor Compliance and CMOD for a General Three-point Bend Beam," Int. J. Fracture, 89 (3), 103-116 (1998).

18. ABAQUS User's Manual Version 5.8, Hibbitt, Karlsson \& Sorensen, Inc. (1997).

19. Nishioka, T. and Atluri, S., "Path Independent Integrals, Energy Release Rates, and General Solutions of Near-tip Fields in Mixed-mode Dynamic Fracture Mechanics," Eng. Fracture Mech., 18, 1-22 (1983).

20. Nishioka, T., "On the Dynamic J Integral in Dynamic Fracture Mechanics," in G. P. Cherepanov (ed), "FRACTURE: A Topical Encyclopedia of Current Knowledge, Dedicated to Alan Arnold Griffith," Krieger Publishing, Malabar, FL, USA, 575-617 (1998). 